\title{
Are Axillary Lymph Nodes Still Relevant in Breast Cancer ?
}

\author{
David M. Euhus, MD
}

Johns Hopkins Hospital, Baltimore

The importance of axillary nodal metastases in breast cancer has been recognized at least since the time of Wilhelm Fabry (1560-1634), who described axillary nodal excision in conjunction with primary tumor surgery. ${ }^{1}$ Understanding precisely what axillary metastases mean has been a work in progress for centuries. By the 18th century breast cancer progression was envisioned as an orderly process beginning in the breast, spreading to nodal basins, and then disseminating to distant sites. In the late 19th century William Halstead popularized the notion that radical nodal surgery could interrupt this progression and save lives. ${ }^{2}$ This view was challenged by Devitt in 1962 based on retrospective data that failed to show a survival advantage for radical nodal surgery. ${ }^{3} \mathrm{He}$ astutely recognized that "...breast cancer patients do not do poorly because they have regional lymph node metastases, rather they have these metastases when they do poorly". ${ }^{4}$ The randomized prospective NSABP B-04 trial, which was first reported in 1977, confirmed that the addition of axillary dissection to mastectomy does not improve distant diseasefree or overall survival. ${ }^{5}$ In a 1980 review Bernard Fisher asserted that "...breast cancer is a systemic disease, likely at its inception," and "The positive lymph node is the reflection of an interrelationship that permits the development of metastases rather than the instigator of distant disease" ${ }^{6}$ Identifying a lymph node metastasis is only the crudest possible indicator that a primary tumor possesses the machinery to thrive outside of the breast in a host who lacks the capacity to prevent it. Though there is considerable overlap between the tumor skill set required to generate a lymph node metastasis and the skill set required

(C) Society of Surgical Oncology 2014

First Received: 23 July 2014;

Published Online: 26 August 2014

D. M. Euhus, MD

e-mail: deuhus1@jhmi.edu to proliferate in a distant organ, the study by Gangi et al. ${ }^{7}$ in this issue of the Annals reminds us that lymph node metastases are neither necessary nor sufficient for the generation of lethal distant metastatic disease.

The specific observation was that tumor subtype, approximated by immunohistochemical staining for estrogen receptor, progesterone receptor, and HER2/neu, did not independently predict lymph node positivity, though young age, larger tumors, higher grade, and lymphovascular invasion did. Breast cancer intrinsic subtype, ascertained by gene expression profiling, is known to predict breast cancer outcome. ${ }^{8}$ Immunohistochemistry provides only an inexact approximation of these intrinsic subtypes, and the 3-marker panel used by these investigators is inferior to larger panels that include EGFR, cytokeratins, and Ki67. ${ }^{9,10}$ The authors focus on triple negative breast cancer, which is a reasonable immunohistochemistry classification, but it must be recognized that this defines a fairly heterogeneous group of tumors and additional markers are required to more closely approximate the truly poor prognosis basal phenotype. ${ }^{11}$ Nevertheless, the conclusion that triple negative breast cancer, though associated with a poor prognosis, is not associated with a higher rate of lymph node metastases is consistent with prior studies suggesting that basal phenotype breast is actually associated with a lower rate of lymph node metastases than hormone-sensitive subtypes. ${ }^{12}$ These tumors clearly possess the machinery to disseminate and grow in distant organs, but some feature of the tumor-host interaction frequently precludes establishment of nodal metastases. Whether this reflects a deficiency in the tumors or an efficiency in the nodes is not known.

Axillary nodal status has long been recognized as one of the strongest predictors of breast cancer recurrence and mortality. ${ }^{13}$ In the wake of rapid advances in molecular profiling, this role is appropriately being challenged, but much work is still required if we are to obtain the same information about tumor-host interactions through other 
means. Though imperfect, the axillary lymph node still serves as an in vivo biological crucible for determining (1) whether tumor cells have gained access to the circulation and (2) whether the cells possess the right machinery to thrive outside of the breast in a specific host. On the first count, when tumor cells are identifiable in a lymph node, it is a certainty that they have gained access to the blood stream. This is because lymph nodes are designed to receive only a fraction of the afferent lymphatic flow; the balance transits directly into venules through lymphovenous shunts in order to maintain a low-pressure system and avoid edema. ${ }^{14}$ Blood assays may provide more direct evidence of hematogenous dissemination, even in the absence of nodal growth. Circulating tumor cells hold some promise in this regard, but additional work is required to improve sensitivity and clinical usability. ${ }^{15}$ Getting into the circulation is a trivial task for tumor cells. ${ }^{16}$ Growing in distant organs requires both a specialized tumor skill set and a cooperative host environment. ${ }^{17}$ Macrometastatic burden in an axillary lymph node tells us something about the interaction between the tumor and the host that will be difficult to derive from analysis of the primary tumor alone. Multigene assays are making progress in this regard, especially for estrogen receptor positive tumors, and there is also progress toward routinely quantifying specific subpopulations of cells in primary tumors capable of mediating invasion and metastases. ${ }^{18,19}$ However, none of these approaches incorporate information about the specific host environment to reliably predict metastatic potential for an individual. Though lymph node metastases provide a wealth of biological information about tumor cell dissemination and tumor-host interaction, they fail as predictive biomarkers. That is, they cannot tell us what specific treatment is likely to be effective in an individual. Molecular profiling of tumors is showing some promise in this regard. ${ }^{20,21}$

Finally, advances in systemic treatment and radiation therapy have massively reduced the risk of regional relapse in patients with residual axillary disease after primary surgery. This has decreased from $38 \%$ for NSABP B-04 published in 1977 to $3 \%$ for ACoSOG Z11 published in $2010 .^{22,23}$ Regional recurrence can be disabling. It would be valuable to develop approaches for recognizing patients at high risk for regional relapse based on molecular and biological features of the positive sentinel node.

The axillary lymph node remains a powerful personalized in vivo bioassay for recognizing hematogenous dissemination and a tumor-host interaction that is favorable for extramammary tumor growth. Though its failings, particularly in the setting of basal-type breast cancer, are becoming apparent, much work is still required to derive the same information by molecular profiling.

\section{REFERENCES}

1. Yalom M. A History of the Breast. New York: Alfred A. Knopf; 1997.

2. Halstead W. The results of operations for cure of cancer of the breast performed at Johns Hopkins Hospital. Johns Hopkins Hosp Bull. 1894;4:497.

3. Devitt JE. The influence of conservative and radical surgery on the survival of patients with breast cancer. Can Med Assoc J. 1962;87:906-10.

4. Devitt JE. The significance of regional lymph node metastases in breast carcinoma. Can Med Assoc J. 1965;93:289-93.

5. Fisher B, Montague E, Redmond C, Barton B, Borland D, Fisher $\mathrm{ER}$, et al. Comparison of radical mastectomy with alternative treatments for primary breast cancer. A first report of results from a prospective randomized clinical trial. Cancer. 1977;39:2827-39.

6. Fisher B, Redmond C, Fisher ER. The contribution of recent NSABP clinical trials of primary breast cancer therapy to an understanding of tumor biology-an overview of findings. Cancer. 1980;46:1009-25.

7. Gangi A, Mirocha J, Leong T, Giuliano AE. Triple-negative breast cancer is not associated with increased likelihood of nodal metastases. Ann Surg Oncol. 2014. doi:10.1245/s10434-014-3989-7.

8. Sørlie T, Perou CM, Tibshirani R, Aas T, Geisler S, Johnsen H, et al. Gene expression patterns of breast carcinomas distinguish tumor subclasses with clinical implications. Proc Natl Acad Sci U $S$ A. 2001;98:10869-74.

9. Nielsen TO, Parker JS, Leung S, Voduc D, Ebbert M, Vickery T, et al. A comparison of PAM50 intrinsic subtyping with immunohistochemistry and clinical prognostic factors in tamoxifentreated estrogen receptor-positive breast cancer. Clin Cancer Res. 2010;16:5222-32.

10. Voduc KD, Cheang MC, Tyldesley S, Gelmon K, Nielsen TO, Kennecke H. Breast cancer subtypes and the risk of local and regional relapse. J Clin Oncol. 2010;28:1684-91.

11. Cheang MC, Voduc D, Bajdik C, Leung S, McKinney S, Chia SK, et al. Basal-like breast cancer defined by five biomarkers has superior prognostic value than triple-negative phenotype. Cancer Res. 2008;14:1368-76.

12. Crabb SJ, Cheang MC, Leung S, Immonen $\mathrm{T}$, Nielsen TO, Huntsman DD, et al. Basal breast cancer molecular subtype predicts for lower incidence of axillary lymph node metastases in primary breast cancer. Clin Breast Cancer. 2008;8:249-56.

13. Nemoto T, Vana J, Bedwani RN, Baker HW, McGregor FH, Murphy GP. Management and survival of female breast cancer: results of a national survey by the American College of Surgeons. Cancer. 1980;45:2917-24.

14. Fisher B, Fisher ER. The interrelationship of hematogenous and lymphatic tumor cell dissemination. Surg Gynecol Obstet. 1966;122:791-8.

15. King JD, Casavant BP, Lang JM. Rapid translation of circulating tumor cell biomarkers into clinical practice: technology development, clinical needs and regulatory requirements. Lab Chip. 2014;14:24-31.

16. Chambers AF, Naumov GN, Vantyghem SA, Tuck AB. Molecular biology of breast cancer metastasis. Clinical implications of experimental studies on metastatic inefficiency. Breast Cancer Res. 2000;2:400-7.

17. Kaplan RN, Riba RD, Zacharoulis S, Bramley AH, Vincent L, Costa $\mathrm{C}$, et al. VEGFR1-positive haematopoietic bone marrow progenitors initiate the pre-metastatic niche. Nature. 2005;438:820-7.

18. Rouzier R, Pronzato P, Chereau E, Carlson J, Hunt B, Valentine WJ. Multigene assays and molecular markers in breast cancer: systematic review of health economic analyses. Breast Cancer Res Treat. Jun 2013;139(3):621-637. 
19. Cheung KJ, Gabrielson E, Werb Z, Ewald AJ. Collective invasion in breast cancer requires a conserved basal epithelial program. Cell. 2013;155:1639-51.

20. Sparano JA, Paik S. Development of the 21-gene assay and its application in clinical practice and clinical trials. J Clin Oncol. 2008;26:721-8.

21. Frampton GM, Fichtenholtz A, Otto GA, Wang K, Downing SR, $\mathrm{He} \mathrm{J}$, et al. Development and validation of a clinical cancer genomic profiling test based on massively parallel DNA sequencing. Nat Biotechnol. 2013;31:1023-31.
22. Fisher B, Jeong JH, Anderson S, Bryant J, Fisher ER, Wolmark N. Twenty-five-year follow-up of a randomized trial comparing radical mastectomy, total mastectomy, and total mastectomy followed by irradiation. New Engl J Med. 2002;347:567-75.

23. Giuliano AE, McCall L, Beitsch P, Whitworth PW, Blumencranz $\mathrm{P}$, Leitch AM, et al. Locoregional recurrence after sentinel lymph node dissection with or without axillary dissection in patients with sentinel lymph node metastases: the American College of Surgeons Oncology Group Z0011 randomized trial. Ann Surg. 2010;252:426-32; discussion 432-3. 